\title{
A new era in blood and lymphatic cancer biology and therapy
}

This article was published in the following Dove Press journal:

Blood and Lymphatic Cancer:Targets and Therapy

I March 201 |

Number of times this article has been viewed

\section{David Dingli \\ Division of Hematology and Department of Internal Medicine, Mayo Clinic, Rochester, MN, USA}

Correspondence: David Dingli Mayo Clinic, Division of Hematology, 200 First Street SW, Rochester, MN 55905, USA

Tel +I 5072843178

$\mathrm{Fax}+\mathrm{I} 5072662122$

Email dingli.david@mayo.edu
Tumors derived from the transformation of hematopoietic or lymphoid cells are increasing in incidence ${ }^{1}$ and with improvements in therapy, their prevalence is also growing. The increasing availability of more sophisticated molecular tools is refining the definition of these diseases ${ }^{2}$ and now more than ever, we are on the verge of 'personalized medicine'. No disease is as personal as cancer. The current view of tumorigenesis is that somatic cells serially acquire mutations that lead to the malignant phenotype, ${ }^{3,4}$ a state characterized by loss of cell cycle regulation, resistance to apoptosis, unbridled cellular proliferation, angiogenesis, evasion of the immune response, and ultimately, invasion of other tissues. ${ }^{5,6}$ Although many somatic mutations probably do not provide a reproductive advantage to cells or can even be deleterious, some mutations enhance the reproductive fitness of the cell enabling it to expand into a clone where additional mutations may lead to the full malignant phenotype. Given that evolution is the result of reproduction, mutation and selection, cancer is a natural consequence, especially in large multicellular organisms that can live for many years. ${ }^{7}$ Exposure to genotoxic agents (chemicals, viruses, radiation) or the response to chronic injury increases the risk of transformation since at some level, the risk is related to the number of cells that are dividing and how often they divide. It is not yet clear how many mutations are required to lead to the cancer phenotype but perhaps with very few exceptions, one mutation is not enough to lead to neoplastic transformation and disease.

In most tissues (including hematopoiesis) there is significant cell turnover but the majority of cells do not survive for long, and the amplifying population of cells is generally maintained by a small population of tissue-specific stem cells that in general replicate slowly. ${ }^{8}$ It is possible that evolution selected for this architecture to minimize the risk of acquisition and maintenance of mutant cells and therefore essentially limit the risk of cancer. ${ }^{3,4}$ One can consider all cells as continuously at risk of acquiring mutations that may bring them a step closer to the malignant phenotype. In essence, cells explore many genotype/phenotype possibilities in an aimless fashion, but if the environment provides an advantage for a clone this will expand and could lead to disease. This relatively simple view can explain the significant genetic heterogeneity that is being discovered in tumors that arise from the same tissue. ${ }^{910}$ Although some genetic defects may be shared, recent sequencing studies show that i) malignant cells harbor many mutated genes, ii) signaling pathways can exhibit significant cross talk and therefore be quite redundant, and iii) the spectrum of oncogenic mutations is much wider than oncogenes, tumor suppressor genes, 
or miRNA. ${ }^{9-11}$ The latter do not include only genes that lead to genomic instability, but also those that provide mechanisms of immune evasion and altered metabolic phenotype. When all of these are considered together, one can quickly see how each tumor is a highly personal problem - in essence 'me gone wrong'.

This intertumor heterogeneity presents a therapeutic problem, since the relevant mutations that are primarily responsible for the growth of the tumor (driver mutations) may not be obvious and to date, we have no clear way of distinguishing between driver and passenger mutations. This is an area that requires more research and the interactions between molecular biologists and biomathematicians are critical. The latter can provide the necessary theoretical framework to understand in a logical and consistent way the large amounts of data being generated by the 'omics' revolution. Generating data is not the problem any more ultra-deep sequencing of acute leukemia, lymphoma, multiple myeloma and other tumors will soon be routine. One can envisage in the near future a new classification of tumors - not based on the cell of origin but on what the relevant therapeutic targets may be for that patient. Ultimately, the type and efficacy of therapy is much more important than the actual name of the disease. We already know that what is called one disease is in effect a spectrum of illnesses and that patients respond differently to the same therapy.

Despite this increasing heterogeneity, current paradigms in cancer therapy suggest that in most tumors, one gene is often the master of ceremonies or the sine qua non that is responsible for the major manifestations of the disease. The list of such clinical scenarios is increasing. Perhaps the best example is $B C R-A B L$ in chronic myeloid leukemia. ${ }^{12}$ Therapy with $A B L$ kinase inhibitors such as imatinib, nilotinib or dasatinib leads to remarkable responses and have transformed the natural history of this disease. ${ }^{13}$ Other examples include i) the use of alltrans retinoic acid and arsenic trioxide in acute promyelocytic leukemia that have changed a rapidly fatal acute leukemia into one of the most curable, ${ }^{14}$ ii) imatinib therapy for PDGFRdependent clonal eosinophilic disorders with mastocytosis, ${ }^{15,16}$ and iii) recent studies of the impact of $J A K$ inhibitors in patients with chronic myeloid neoplasms. ${ }^{17}$ More and more therapeutic targets will be identified and small molecules developed that selectively inhibit the function of such mutant genes and provide better control of the disease. Another revolution has been the introduction of therapeutic antibodies with rituximab being the best success story for patients with CD20 positive lymphomas. ${ }^{18}$ Technological developments such as multicolor flow cytometry and quantitative reverse transcriptase polymerase chain reaction have also enhanced our ability to detect minimal residual disease. Functional imaging using positron emission tomography and magnetic resonance spectroscopy are providing unprecedented information about residual disease and its metabolic activity. These diagnostic modalities have enabled the intensification of therapy and deeper responses that may translate into improved survival.

Although it is often desirable to use single agents for therapy, and they can be effective in selective circumstances, more often than not, combination chemotherapy is required for curative therapy. Perhaps the flagship combinations have been (R)-CHOP for non-Hodgkin lymphoma ${ }^{18}$ and MOPP or ABVD for Hodgkin disease. ${ }^{19}$ The evolution of combination chemotherapy has also changed the therapeutic landscape for acute lymphoblastic leukemia, especially in the pediatric age group. Similar attempts continue for many other hematopoietic malignancies including multiple myeloma, lymphoma, acute myeloid leukemia and chronic lymphocytic leukemia.

No discussion about carcinogenesis is complete without mention of the concept of cancer stem cells. Tumors have an architecture similar to normal tissues in that a considerable number of cells undergo rapid turnover, and that most of these tumor cells are not able to maintain the tumor tissue. Over the last few years, the concept of cancer stem cells or cancer initiating cells has emerged and is now generally accepted. ${ }^{8,20}$ Cancer stem cells have now been described for a multitude of tumors, although initially they were described in acute myeloid leukemia. ${ }^{20} \mathrm{~A}$ major question relates to the origin of these cancer stem cells - are they due to the acquisition of oncogenic mutations in normal stem cells or can more differentiated cells re-acquire stem cell-like properties? The answer to this question is that either can occur and the evidence again comes from hematologic malignancies. Mutations in normal hematopoietic stem cells lead to diseases such as chronic myeloid leukemia ${ }^{21}$ and the other chronic myeloid neoplasms. ${ }^{2}$ However, mutations in progenitor cells can lead to the acquisition of stem cell-like behavior in cells that drive various forms of acute leukemia, including acute promyelocytic leukemia. ${ }^{22,23}$ The role of the cancer stem cell in disease progression, response to therapy and relapse is an area of active investigation. The question of whether cancer stem cells need to be eliminated to cure the tumor is at present unanswered.

Allogeneic and autologous hematopoietic stem/progenitor cells transplantation has saved thousands of lives. These procedures are safer now than ever before thanks to improvements in supportive care. ${ }^{24}$ The field continues to evolve with the introduction of novel conditioning regimens, including nonmyeloablative conditioning, cord blood transplantation and in the near future, gene therapy approaches to modify progenitor cells prior to infusion. 
All of these therapeutic modalities come at a price - and by this I am not referring only to the monetary costs, important as these may be. In these times of economic austerity, one must not forget the financial pressures that medications impose on patients and their families, as well as the health care system. In addition, there are other major costs including the burden of side effects from the medications, the frequency of visits and monitoring that is required that potentially increase the psychologic stress on the patient and time away from work. The quality of life of patients and how this is altered by the disease and its therapy are major considerations. These issues all influence patient compliance with therapy and therefore can alter the outcome of our interventions in a complex fashion. The patient is more than the disease and all of us react differently when confronted with specific situations including illness. As we care for our patients, we have to consider patients in their totality and treat them and not the disease alone.

We welcome contributions on the biology and therapy of hematopoietic and lymphatic tumors. Blood and Lymphatic Cancer: Targets and Therapy is interested in the holistic care of the patient and will consider all aspects of therapy for these neoplasms.

\section{Acknowledgments}

This work is supported by Mayo Clinic and the Minnesota Partnership for Biomedical Informatics and Medical Genomics.

\section{Disclosures}

The author has no disclosures to make.

\section{References}

1. Jemal A, Siegel R, Ward E, Hao Y, Xu J, Thun MJ. Cancer statistics, 2009. CA Cancer J Clin. 2009;59(4):225-249.

2. Jaffe ES, Harris NL, Stein H, Vardiman JW. Pathology and Genetics of Tumours of Haematopoietic and Lymphoid tissues. Lyon, France: IARC Press; 2001.

3. Traulsen A, Pacheco JM, Luzzatto L, Dingli D. Somatic mutations and the hierarchy of hematopoiesis. Bioessays. 2010;32(11):1003-1008.
4. Nowak MA, Michor F, Iwasa Y. The linear process of somatic evolution. Proc Natl Acad Sci U SA. 2003;100(25):14966-14969.

5. Hanahan D, Weinberg RA. The hallmarks of cancer. Cell. 2000; 100(1):57-70.

6. Vogelstein B, Kinzler KW. Cancer genes and the pathways they control. Nat Med. 2004;10(8):789-799.

7. Lopes JV, Pacheco JM, Dingli D. Acquired hematopoietic stem-cell disorders and mammalian size. Blood. 2007;110(12):4120-4122.

8. Reya T, Morrison SJ, Clarke MF, Weissman IL. Stem cells, cancer, and cancer stem cells. Nature. 2001;414(6859):105-111.

9. Sjoblom T, Jones S, Wood LD, et al. The consensus coding sequences of human breast and colorectal cancers. Science. 2006;314(5797): 268-274.

10. Greenman C, Stephens P, Smith R, et al. Patterns of somatic mutation in human cancer genomes. Nature. 2007;446(7132):153-158.

11. Mardis ER, Ding L, Dooling DJ, et al. Recurring mutations found by sequencing an acute myeloid leukemia genome. $N$ Engl J Med. 2009; 361(11):1058-1066.

12. Druker BJ. Imatinib: paradigm or anomaly? Cell Cycle. 2004;3(7): 833-835.

13. Druker BJ, Guilhot F, O'Brien SG, et al. Five-year follow-up of patients receiving imatinib for chronic myeloid leukemia. $N$ Engl J Med. 2006;355(23):2408-2417.

14. Sanz MA, Martin G, Diaz-Mediavilla J. All-trans-retinoic acid in acute promyelocytic leukemia. N Engl J Med. 1998;338(6):393-394.

15. Gleich GJ, Leiferman KM, Pardanani A, Tefferi A, Butterfield JH. Treatment of hypereosinophilic syndrome with imatinib mesilate. Lancet. 2002;359(9317):1577-1578.

16. Pardanani A, Elliott $M$, Reeder $T$, et al. Imatinib for systemic mast-cell disease. Lancet. 2003;362(9383):535-536.

17. Verstovsek S, Kantarjian H, Mesa RA, et al. Safety and efficacy of INCB018424, a JAK1 and JAK2 inhibitor, in myelofibrosis. $N$ Engl J Med. 2010;363(12):1117-1127.

18. Coiffier B, Lepage E, Briere J, et al. CHOP chemotherapy plus rituximab compared with CHOP alone in elderly patients with diffuse large-B-cell lymphoma. $N$ Engl J Med. 2002;346(4):235-242.

19. Santoro A, Bonadonna G, Valagussa P, et al. Long-term results of combined chemotherapy-radiotherapy approach in Hodgkin's disease: superiority of ABVD plus radiotherapy versus MOPP plus radiotherapy. J Clin Oncol. 1987;5(1):27-37.

20. Bonnet D, Dick JE. Human acute myeloid leukemia is organized as a hierarchy that originates from a primitive hematopoietic cell. Nat Med. 1997;3(7):730-737.

21. Marley SB, Gordon MY. Chronic myeloid leukaemia: stem cell derived but progenitor cell driven. Clin Sci (Lond). 2005;109(1):13-25.

22. Krivtsov AV, Twomey D, Feng Z, et al. Transformation from committed progenitor to leukaemia stem cell initiated by MLL-AF9. Nature. 2006;442(7104):818-822.

23. Guibal FC, Alberich-Jorda M, Hirai H, et al. Identification of a myeloid committed progenitor as the cancer-initiating cell in acute promyelocytic leukemia. Blood. 2009;114(27):5415-5425.

24. Gooley TA, Chien JW, Pergam SA, et al. Reduced mortality after allogeneic hematopoietic-cell transplantation. $N$ Engl J Med. 2011; 363(22):2091-2101
Blood and Lymphatic Cancer: Targets and Therapy

\section{Publish your work in this journal}

Blood and Lymphatic Cancer: Targets and Therapy is an international, peer-reviewed, open access journal focusing on blood and lymphatic cancer research, identification of therapeutic targets and the optimal use of preventative and integrated treatment interventions to achieve improved outcomes, enhanced survival and quality of life for the

\section{Dovepress}

cancer patient. The manuscript management system is completely online and includes a very quick and fair peer-review system. Visit http://www.dovepress.com/testimonials.php to read real quotes from published authors. 